\title{
Study the Effect of Convolvulus arvensis on the Contraction of Isolated Vascular Smooth Muscle Fibers Portal Vein
}

\author{
Wael Al-Aghawani, Bassel Hussein \\ Faculty of Pharmacy, Al-Sham Private University (ASPU), Damascus, Syria \\ Email:w.a.foph@aspu.edu.sy,wael.alaghawani@gmail.com,b.h.foph@aspu.edu.sy
}

How to cite this paper: Al-Aghawani, W. and Hussein, B. (2022) Study the Effect of Convolvulus arvensis on the Contraction of Isolated Vascular Smooth Muscle Fibers Portal Vein. Open Access Library Journal, 9: e8407.

https://doi.org/10.4236/oalib.1108407

Received: January 29, 2022

Accepted: February 25, 2022

Published: February 28, 2022

Copyright $\odot 2022$ by author(s) and Open Access Library Inc.

This work is licensed under the Creative Commons Attribution International License (CC BY 4.0).

http://creativecommons.org/licenses/by/4.0/

\begin{abstract}
Background: Convolvulus arvensis L. (Convolvulaceae) possess several biological properties and has been used in the treatment of hepatic obstructions. The present study aimed to evaluate the relaxant effects of the alcoholic extract of $C$. arvensis on both spontaneous and phenylephrine-induced contraction of isolated rat portal vein. Materials and Methods: First, the effect of the extracts was examined on spontaneous rhythmic contraction of longitudinal-cut portal strips, the extract was added cumulatively to tissues' baths. In another set of experiments, two groups of portal strips were used, one group was intact endothelium and the other was without endothelium. They were contracted by phenylephrine and then the extract was added similarly as previously. The changes in contraction were measured and recorded by isolated organ system (I.O.S). Results: The previous extract exhibited profound relaxant effect on both spontaneous and phenylephrine-induced contraction of portal preparations. The effect of the extract was the same in both intact and denuded endothelium portal strips. Conclusion: The extract of Convolvulus arvensis has obvious relaxing effects on both rhythmic and phenylephrine-induced contraction with no role for endothelium. Further studies are encouraged to illustrate the mechanisms and to isolate the related active compound(s).
\end{abstract}

\section{Subject Areas}

Pharmacology

\section{Keywords}

Convolvulus arvensis, Portal Vein, Phenylephrine, Spontaneous Contraction 


\section{Introduction}

Convolvulus arvensis L., also known as Field bindweed, is a persistent, perennial vine of the morning-glory family (Convolvulaceae) which spreads by rhizome and seed [1]. It is a weak-stemmed, prostrate plant that can twine and may form dense tangled mats. Stems may reach the high of $1.5 \mathrm{~m}$ or more and the extensive roots penetrate deeply into the soil. The leaf has distinctive arrowhead shapes with pointed lobes at the bases. Petals are generally white to very pale pink.

Convolvulus arvensis L. is native to Europe and Asia, but is now a cosmopolitan species that grows in tropical and Mediterranean climates [1]. Because of its wide distribution, Convolvulus arvensis is considered one of the worst weeds [2]. Its impact on agricultural lands is well documented especially in temperate zones but the threat it poses to natural areas is unclear [2]. It may be mildly toxic to some grazing animals [3].

This plant has some important active groups and ingredients such as Glycosides [3] [4] [5], flavonoids, alkaloids, resin and scopoletin [3]. It has some uses and the tea made from the flowers and leaves is laxative and also used in the treatment of fever and wounds. The extracts of it show profound promise as anticancer agents [4], and some reports mentioned anti-spasm properties of these extracts [6]. However, there is no report in literature on the vascular action of Convolvulus arvensis $\mathrm{L}$. extracts. The aim of the present study was to evaluate the relaxing effects of $C$. arvensis ethanolic extract on the contraction induced by phenylephrine in rat isolated portal vein, and to examine the possible role of the endothelium and potassium channels in these pharmacologic effects.

\section{Materials and Methods}

\subsection{Materials}

\subsubsection{Plant Sample Collection and Extraction}

The plant was collected from countryside of Damascus in summer 2020 and identified at the faculty of science, Damascus University. The leaves of $C$. arvensis were dried in dark and room temperature. The plant extract was prepared by decoction followed by lyophylization [7]. Alcoholic extraction was performed by maceration method where the ground dried leaves $(10 \mathrm{~g})$ of the plant were overnight shaken in a $100 \mathrm{ml}$ mixture of $30 \mathrm{ml}$ de-ionized water and $70 \mathrm{ml}$ ethanol. After filtration, the ethanol was evaporated under vacuum and the remaining aqueous extract was lyophilized to dryness. Dry extract yield was approximately $5 \%(\mathrm{w} / \mathrm{w})$ of the crude plant material. Working solutions of extract were prepared daily at a concentration of $80 \mathrm{mg} / \mathrm{ml}$ in distilled water.

\subsubsection{Drugs}

The following chemicals and drugs were used: phenylephrine, acetylcholinehydrochloride, (Sigma). Glibenclamide was dissolved in dimethyl sulfoxide (DMSO). Other drugs were dissolved in distilled water and DMSO at $0.2 \%(\mathrm{v} / \mathrm{v}) \mathrm{did}$ not 
affect the extract induced relaxation.

\subsubsection{Animals}

Adult male Sprague Dawly rats weighing 200 - 250 grams were obtained from the Experimental Animal Center of the Agriculture Research Department, Damascus and used in the present study. Ethical approval was obtained from the Institutional Research Review Board of the Faculty of Pharmacy, International University of Science and Technology (IUST), Syria. All efforts were made to avoid animal suffering.

\subsection{Study Protocol}

\subsubsection{Preparation of the Isolated Portal Vein Strips [8] [9]}

The rats were euthanized after anesthetizing them with sodium phenobarbitone (50 mg/kg; intravenously), the portal vein was excised and adhesive tissues were carefully cleared away. The portal vein was cut into strips (length of approximately $1.5 \mathrm{~cm}$ ) that contain obvious smooth fibers. The isolated strips were mounted in a $20 \mathrm{ml}$ organ bath containing Krebs' solution (pH 7.4) at $37^{\circ} \mathrm{C}$ and continuously aerated with a gas mixture $95 \% \mathrm{O}_{2}-5 \% \mathrm{CO}_{2}$. The Krebs' solution contained the following composition (in mmol/L): $\mathrm{NaCl} 120, \mathrm{KCl} 5.5, \mathrm{MgCl}_{2} \cdot 6 \mathrm{H}_{2} \mathrm{O}$ 1.2, $\mathrm{NaH}_{2} \mathrm{PO}_{4}$ 1.56, $\mathrm{CaCl}_{2} 2.5, \mathrm{NaHCO}_{3} 20$, and D-glucose 10.1. The portal strips preparations were mounted between two stainless steel wire in the organ bath, under an applied resting tension of $0.5 \mathrm{~g}$. Isometric tension change was recorded continuously on a two-channel physiological recorder (Dei lierre electronique, France).

Before starting the experiments, all preparations were allowed to equilibrate for $60 \mathrm{~min}$, during which time Krebs' solution was replaced every $20 \mathrm{~min}$. the experiments were carried only on strips that exhibit spontaneous contraction during the first 30 minutes, Figure 1.

Working solutions were made on the day of experiments by dissolving $20 \mathrm{mg}$ of extract in 250 micro liter of Krebs solution. The control group received the same volumes of only Krebs solution.

\subsubsection{The Effect of Extract on the Spontaneous Contraction}

To evaluate the effect of extract on the spontaneous contractions of vein strips, the extract was added cumulatively to the experimental group (Figure 1(a)). The control group received the same volumes of only Krebs solution.

\subsubsection{The Effect of Extract on Phenylephrine-Precontracted Preparation and the Role of Endothelium}

In another set of experiments, the portal vein strips were contracted by phenylephrine $10^{-6} \mathrm{M}$. When the contraction reached the plateau the extract was added cumulatively to induce a concentration-dependent response in the strips (Figure 1(b)). To investigate whether the relaxing response of extract depends on the endothelium, its effect was observed in endothelium-denuded strips and the extract was added in the same manner. The intactness or the denudation of 


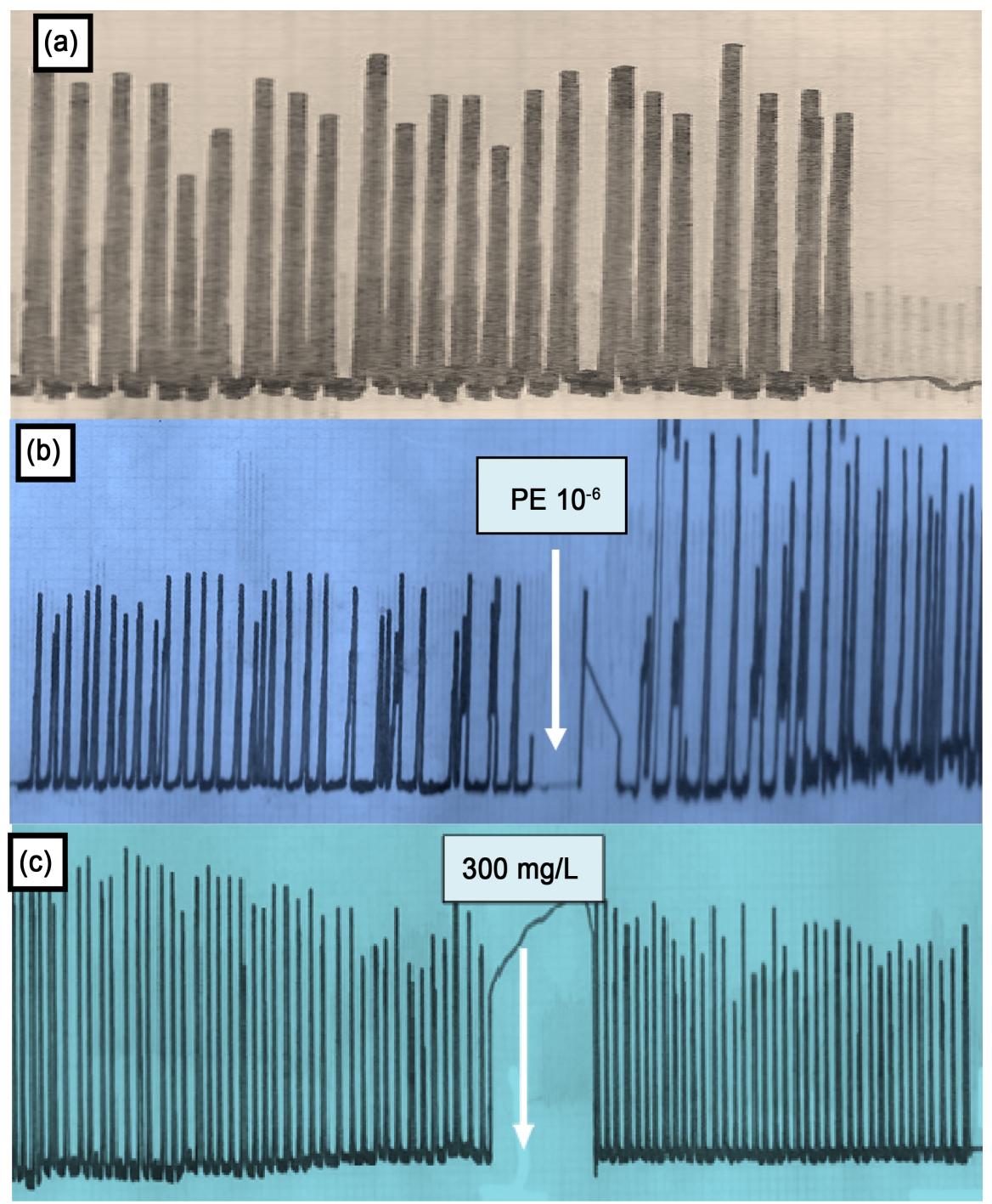

Figure 1. Graph tracing of the spontaneous contraction of portal strips of the control (a), phenylephrine-induced contraction of portal strips (b), and the trace of the Convolvulus arevensis extract's effect on spontaneous contraction (c).

endothelium was confirmed by the appearance or the disappearance of relaxant response to acetylcholine $(10 \mu \mathrm{mol} / \mathrm{L})$ in $\mathrm{PE}\left(1 \times 10^{-6} \mathrm{~mol} / \mathrm{L}\right)$ pre-contracted strips (Figure 1(c)).

\subsubsection{Statistical Analysis}

The relaxant response to the extract was expressed as a percentage of the extract-induced relaxation which was calculated as doses of the extract inhibited gradually the basal contraction initially induced by phenylephrine and expressed as $\%$. $\mathrm{IC}_{50}$ values were obtained as the drug concentration causing a half-maximum relaxation and were calculated by non-linear regression analysis of the concentration-response curves using all the data point. Results are expressed as the Means \pm S.E.Ms for $\mathrm{n}$ separate experiments. Data were analyzed by Student $\mathrm{t}$-test and a probability of less than 0.05 was regarded significant. 


\section{Results}

\subsection{Effect of the Extract on Spontaneous Contraction of Vein Strips}

Convolvulus arvensis extract produced concentration-dependent inhibition of spontaneous contraction exhibited by vein strips compared with the control group, $\mathrm{P}<0.05$. ( $\mathrm{IC}_{50}=620 \mathrm{mg} / \mathrm{L}$ ), the effect was dose-dependent (Figure $1(\mathrm{c})$, Figure 2).

\subsection{Relaxing Effect of $C$. arvensis in Phenylephrine-Induced Contraction Strips and the Role of Endothelium}

In the phenylephrine-preconstricted vein strips, $C$. arvensis extract produced

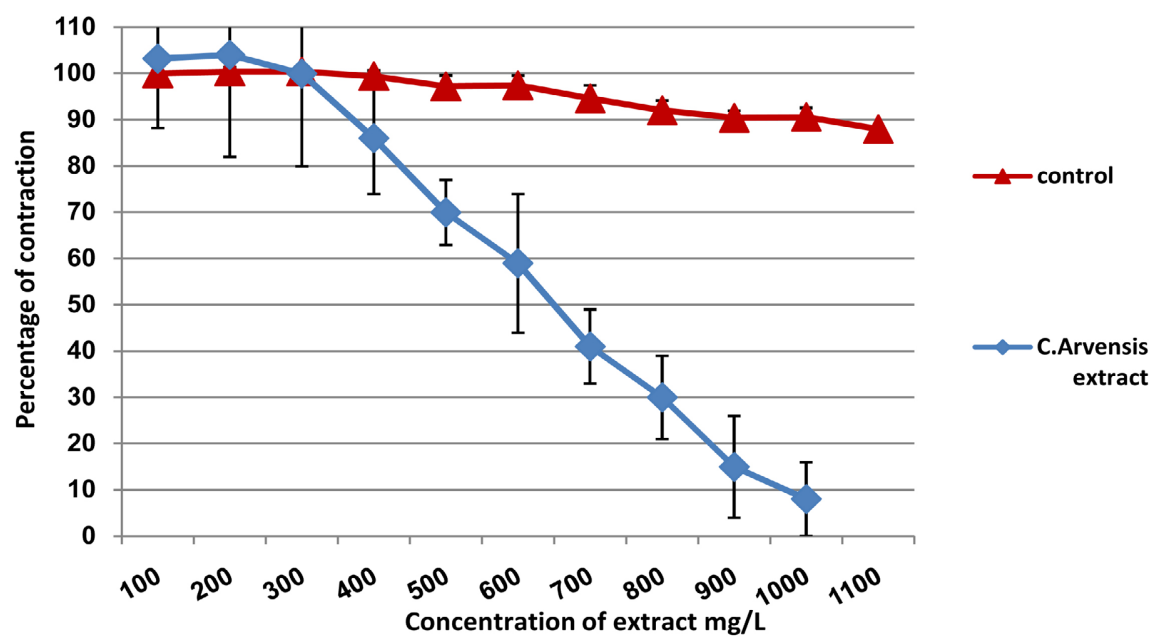

Figure 2. Effect of Convolvulus arevensis extract on spontaneous contraction of vein strips.

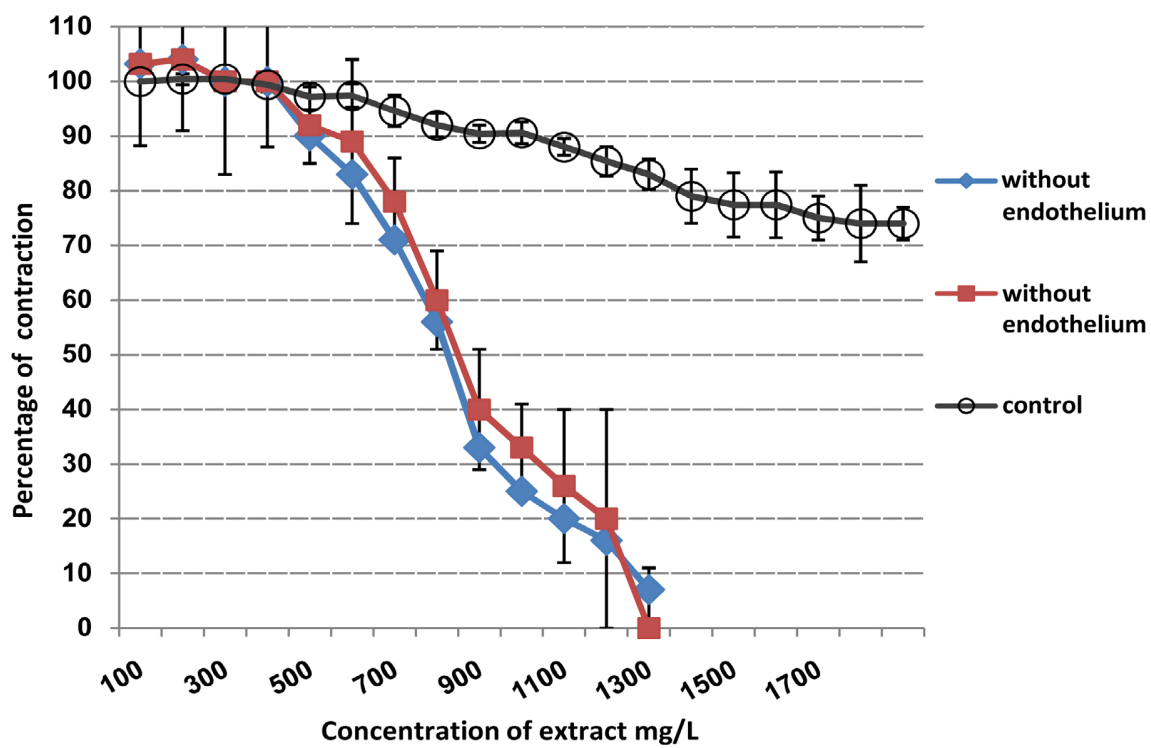

Figure 3. Effect of Convolvulus arevensis extract on Phenylephrine-induced contraction of vein strips. 
concentration-dependent relaxation to a similar extent in the absence and presence of endothelium compared with the control group $\left(\mathrm{IC}_{50}=920 \mathrm{mg} / \mathrm{L}\right.$ with endothelium and $945 \mathrm{mg} / \mathrm{L}$ without endothelium, $\mathrm{P}<0.05$, Figure 3).

\section{Discussion}

The portal vein has many important physiologic characteristics that make it a subject for many researches [10] [11] [12] [13]. In particular those that study the effect of diverse plants or herbal extract on the contraction of this vein as a part of evaluating their effects on cardiovascular system [14] [15]. Part of this interest in portal vein is relevant to its spontaneous contraction [16] [17].

In this study, the extract of Convolvulus arevensis exhibited obvious inhibition of the natural rhythmic contractions that are distinguished the portal vein preparations. The inhibitory concentration of the extract $\left(\mathrm{IC}_{50}\right)$ was $620 \mathrm{mg} / \mathrm{L}$. The relaxation was shown to be dose-dependent that continued until complete elimination of these contractions. The rhythmicity of portal vein is dependent on the movement of calcium ions from intracellular stores and via calcium channels [18] [19]. Our findings could be attributed to the ability of the extract to modulate movement of the endogenous and exogenous calcium ions.

In contraction induced by phenylephrine, the relaxing effect was also dose-dependent and the precontracted aortic rings were returned back to their basal tension. However, the doses needed for this set of experiments were clearly higher than those needed in spontaneous contraction. These relaxing effects were obviously not related to the endothelium. Thus, this refers in part at least, that the mechanism of relaxing effect of Convolvulus arevensis extract is not related to the endothelium derivatives especially nitric oxide [20]. Moreover, phenylephrine increased in the amplitude of the normal rhythmic contraction of vein strips, this sustained contraction is called phasic contraction. The latter is used to evaluate the vasoactivity of various extracts and their constituents [21] [22] [23]. Again this result emphasizes that the mechanism of effect is mostly dependent on reduction in calcium movement across the membrane as well as from intracellular movements.

\section{Conclusion}

The current data shows profound relaxing effects of Convolvulus arvensis are endothelium-independent relaxation mechanisms and are partially mediated through inhibition of calcium entry via surface calcium channels and intracellular $\mathrm{Ca}^{2+}$ release. Further studies on Convolvulus arvensis are justified due to the relative safety of the plant in humans. The main active compounds of the plant should be isolated. The pharmacodynamic characteristics of these ingredients can be defined in order to start the clinical trials in humans.

\section{Conflicts of Interest}

The authors declare no conflicts of interest. 


\section{References}

[1] Huang, Z.F., Liu, Y., Zhang, C.X., Jiang, C.L., Huang, H.J. and Wei, S.H. (2019) Molecular Basis of Natural Tolerance to Glyphosate in Convolvulus arvensis. Scientific Reports, 9, Article No. 8133. https://doi.org/10.1038/s41598-019-44583-8

[2] Razaghi, P. and Zafari, D. (2017) Phoma crystallifera with Phytotoxic Effects and Pathogenic Potential against Field Bindweed (Convolvulus arvensis L.) in Iran. Journal of Applied Microbiology, 122, 1275-1285. https://doi.org/10.1111/jam.13411

[3] Kazinczi, G., Takacs, A. and Horvath, J. (2006) Crop-Weed Competition between Sunflower (Helianthus annuus L.) and Convolvulus arvensis L. in Substitutive Experiments. Communications in Agricultural and Applied Biological Sciences, 71, 781-786.

[4] Fan, B.Y., He, Y., Lu, Y., Yang, M., Zhu, Q., Chen, G.T. and Li, J.L. (2019) Glycosidic Acids with Unusual Aglycone Units from Convolvulus arvensis. Journal of Natural Products, 82, 1593-1598. https://doi.org/10.1021/acs.jnatprod.9b00056

[5] Lu, Y., He, Y., Yang, M. and Fan, B.Y. (2021) Arvensic Acids K and L, Components of Resin Glycoside Fraction from Convolvulus arvensis. Natural Product Research, 35, 2303-2307.

[6] Fan, B.Y., Lu, Y., Yin, H., He, Y., Li, J.L. and Chen, G.T. (2018) Arvensic Acids A-D, Novel Heptasaccharide Glycosidic Acids as the Alkaline Hydrolysis Products of Crude Resin Glycosides from Convolvulus arvensis. Fitoterapia, 131, 209-214. https://doi.org/10.1016/j.fitote.2018.10.029

[7] Al-Aghawani, W. and Naser, I. (2019) Antispasmodic Effects of Salvia officinalis in Isolated Ileum of Rabbit. Pharmacology \& Pharmacy, 10, 223-233.

https://doi.org/10.4236/pp.2019.105019

[8] Atta, A.H. and Mouneir, S.M. (2004) Antidiarrhoeal Activity of Some Egyptian Medicinal Plant Extracts. Journal of Ethnopharmacology, 92, 303-309. https://doi.org/10.1016/j.jep.2004.03.017

[9] Burt, R.P. (2005) Depletion of $\mathrm{Ca}^{2+}$ from Intracellular Stores of the Rat Portal Vein Stimulates a Tonic Contraction. European Journal of Pharmacology, 510, 97-105. https://doi.org/10.1016/j.ejphar.2005.01.021

[10] Datte, J.Y., Ziegler, A. and Tillement, J.P. (1999) Sympathomimetic Effects of Parquetina nigrescens (Periplocaceae) Extract in Isolated Portal Vein Smooth Muscle. General Pharmacology: The Vascular System, 32, 551-556.

https://doi.org/10.1016/S0306-3623(98)00205-5

[11] Shimamura, K., Kimura, S., Zhou, M., Wang, Y., Toba, M., Ohashi, A., Higuchi, T., Kawaguchi, H. and Kitamura, K. (2005) Evidence for the Involvement of the Cyclooxygenase-Metabolic Pathway in Diclofenac-Induced Inhibition of Spontaneous Contraction of Rat Portal Vein Smooth Muscle Cells. Journal of Smooth Muscle Research, 41, 195-206.

[12] Shimamura, K., Toba, M., Kimura, S., Ohashi, A. and Kitamura, K. (2006) Clonidine Induced Endothelium-Dependent Tonic Contraction in Circular Muscle of the Rat Hepatic Portal Vein. Journal of Smooth Muscle Research, 42, 63-74.

[13] Rossignoli Pde, S., Rodrigues, A.D., Tinti, T., Pereira, O.C., Ellinger, F. and Chies, A.B. (2008) The Possible Involvement of Hyperpolarizing Mechanisms in Histamine-Induced Relaxation of the Rat Portal Vein. Journal of Smooth Muscle Research, 44, 129-141.

[14] Amos, S., Akah, P.A., Binda, L., Enwerem, N.M., Ogundaini, A., Wambebe, C., 
Hussaini, I.M. and Gamaniel, K.S. (2003) Hypotensive Activity of the Ethanol Extract of Pavetta crassipes Leaves. Biological and Pharmaceutical Bulletin, 26, 1674-1680.

[15] Chiwororo, W.D. and Ojewole, J.A. (2008) Biphasic Effect of Psidium guajava Linn. (Myrtaceae) Leaf Aqueous Extract on Rat Isolated Vascular Smooth Muscles. Journal of Smooth Muscle Research, 44, 217-229.

[16] Burt, R.P. (2003) Phasic Contractions of the Rat Portal Vein Depend on Intracellular $\mathrm{Ca}^{2+}$ Release Stimulated by Depolarization. The American Journal of Physiology-Heart and Circulatory Physiology, 284, H1808-H1817. https://doi.org/10.1152/ajpheart.00637.2002

[17] Vinogradova, O.O., Yanchuk, P.I. and Pasichnichenko, O.M. (2015) Role of Thromboxane and Leukotrienes in Mechanisms of Contractile Reactions. Fiziologichnyi Zhurnal, 61, 70-74.

[18] Huang, X., Zhao, D., Wang, Z.Y., Zhang, M.L., Yan, Z.Q., Han, Y.F., Lu, H.L., Xu, W.X. and Jiang, Z.L. (2010) Spontaneous Rhythmic Inward Currents Recorded in Interstitial Cells of Rabbit Portal Vein. Cell Biochemistry and Biophysics, 57, 77-85. https://doi.org/10.1007/s12013-010-9085-0

[19] Garcia, F.A., Tanae, M.M., Torres, L.M., Lapa, A.J., de Lima-Landman, M.T. and Souccar, C. (2014) A Comparative Study of Two Clerodane Diterpenes from Baccharis trimera (Less.) DC. on the Influx and Mobilization of Intracellular Calcium in Rat Cardiomyocytes. Phytomedicine, 21, 1021-1025. https://doi.org/10.1016/j.phymed.2014.04.018

[20] Basei, F.L., Cabrini, D.A., Figueiredo, C.P., Forner, S., Hara, D.B., Nascimento, A.F., Ceravolo, G.S., Carvalho, M.H., Bader, M., Medeiros, R. and Calixto, J.B. (2012) Endothelium Dependent Expression and Underlying Mechanisms of Des-Arg9Bradykinin-Induced $\mathrm{B}_{1} \mathrm{R}-$ Mediated Vasoconstriction in Rat Portal Vein. Peptides, 37, 216-224. https://doi.org/10.1016/j.peptides.2012.07.020

[21] Hore, S.K., Choudhury, S., Ahmad, A.H., Garg, S.K. (2013) Withania Somnifera Ameliorates Lead-Induced Augmentation of Adrenergic Response in Rat Portal vein. Indian Journal of Pharmacology, 45, 563-568.

[22] Protić, D., Beleslin-Čokić, B., Novaković, R., Kanjuh, V., Heinle, H., Sćepanović, R., Gojković-Bukarica, L. (2013) Effect of Wine Polyphenol Resveratrol on the Contractions Elicited Electrically or by Norepinephrine in the Rat Portal Vein. Phytotherapy Research, 27, 1685-1693. https://doi.org/10.1002/ptr.4907

[23] Yamakawa, T., Matsutomo, T., Hofmann, T. and Kodera, Y. (2014) Aged Garlic Extract and One of the Constituent, (+)-(2S,3R)-Dehydrodiconiferyl Alcohol, Inhibits Alkaline Phosphatase Activity Induced by Inflammation Factors in Human Vascular Smooth Muscle Cells. Food and Nutrition Sciences, 5, 177-184.

https://doi.org/10.4236/fns.2014.52023 